\title{
Effect of Geometrical Structure to the Performance of Monolithic Dye-Sensitized Solar Cells
}

\author{
Bayu Aditya Nugraha ${ }^{\text {a,* }}$, Shobih ${ }^{\text {b }}$, Jojo Hidayat ${ }^{\text {b }}$, Dahlang Tahir a \\ ${ }^{a}$ Department of Physics \\ Hasanuddin University \\ Jalan Perintis Kemerdekaan KM. 10, Tamalanrea \\ Makassar 90245, Indonesia \\ ${ }^{b}$ Research Center for Electronics and Telecommunication \\ Indonesian Institute of Sciences (P2ET-LIPI) \\ Kompleks LIPI Gedung 20 Lantai 4 Jalan Sangkuriang, Cisitu \\ Bandung 40135, Indonesia
}

\begin{abstract}
Since invented for the first time, researchers in the world were focusing on how to increase the efficiency of dye-sensitized solar cells (DSSC) and reduce of the fabrication cost. Monolithic type of DSSC is one of the best solutions to reduce the fabrication cost due to the elimination of one of transparent conductive oxide (TCO) substrate. In this study, DSSC monolithic was fabricated layer by layer by using screen printing method. There are three layers that printed in each cell namely $\mathrm{TiO}_{2}, \mathrm{ZrO}_{2}$, and carbon before being injected with electrolytes. The geometrical structure of DSSC was varied to find the highest performance. From the I-V characteristics and incident photon-to-current efficiency (IPCE) characterization shows the highest efficiency is $0.137 \%$ and the highest conversion of photons to current occurs at around $510 \mathrm{~nm}$ wavelength, for a structure which has $\mathrm{ZrO}_{2}$ layer not crosses over the no-FTO area, while $\mathrm{TiO}_{2}$ layer half crosses the no-FTO area, this is most likely caused by the imperfection of the $\mathrm{ZrO}_{2}$ layer.
\end{abstract}

Keywords: DSSC, monolithic, geometrical structure, efficiency, I-V, IPCE.

\section{INTRODUCTION}

Nowadays, energy is one of most problems faced by almost every country in the world. This is due to rapid development of the technology, information, industries, and other fields that leading to an increase in energy needs. The dependence on fossil fuels as energy sources causes a reduction in its resources. Current status of world's oil supply is expected to be run out in 23 years, the gas will be run out in 62 years ahead, and coal will be run out in 146 years ahead [1]. The alternative energy which is not expensive and ecofriendly needs to be explored as the solution to reduce the dependency on fossil fuels resources.

One of the potential alternative energy sources is the sun. The sun has produced energy for billions of years. Every hour, the sun beams more energy onto earth than it needs to satisfy global energy needs for an entire year. Solar energy panel system is the technology used to harness the sun's energy and make it usable. As of 2011, the technology produced less than one-tenth of one percent of global energy needs. The solar cell is a device to convert solar energy into electrical energy [2]. Silicon-based solar cells have been massively produced and used in many applications with the efficiency of 15$25 \%$. However, they have some weaknesses such as high cost of fabrication and the need of wide area to place the solar panel [3].

\footnotetext{
* Corresponding Author.

Email: bayuadngrha15@gmail.com

Received: March 29, 2018 ; Revised: July 23, 2018

Accepted: August 02, 2018 ; Published: December 31, 2018

(C) 2018 PPET - LIPI
}

DSSCs differ from the conventional silicon solar cells in a way that they separate the function of light absorption from charge carrier transport. In the case of n-type semiconductor materials, such as $\mathrm{TiO}_{2}$, current is generated when a photon absorbed by a dye molecule gives rise to electron injection into the conduction band of the semiconductor. To complete the circuit, the dye must be regenerated by electron transfers from a redox species in solution which is the reduced at the counter electrode [4].

DSSC has four main module designs, there are parallel connected, Z-interconnected, W-interconnected, and monolithic [5]. Especially for monolithic design, it has many differences with conventional DSSC. First, it only needs one F-doped tin oxide (FTO) glass substrate, meanwhile, the conventional DSSC needs two of it. The other difference is about the charge. In conventional DSSC, the positive and negative charges are separated or located on different FTO substrate. While in monolithic DSSC, the charges are only on one FTO substrate. Another difference is the fabrication process. The coating process is done on both FTO substrate in conventional DSSC. Meanwhile, in monolithic DSSC, the coating process of each layer only done on one FTO glass substrate.

An important development in the design of DSSC is the monolithic design that attempts to eliminate the need for a second FTO glass substrate. Because FTO for these electrodes accounts for $80 \%$ of DSSC-fabrication cost. Additionally, platinum $(\mathrm{Pt})$ that used as counterelectrode is also expensive. For further cost reduction, monolithic DSSC has been fabricated on single FTO 
glass substrates with porous carbon as counterelectrode. Another layer that is used in monolithic DSSC is porous $\mathrm{ZrO}_{2}$ that has two functions, (1) as transportation of electrolyte to dyed porous $\mathrm{TiO}_{2}$ layer; (2) as a spacing insulator to separate dyed $\mathrm{TiO}_{2}$ layer and carbon layer electrically [5]-[6]. According to Thompson et al, the spacer layer such as $\mathrm{ZrO}_{2}$ etc. is not essential in monolithic structures, without spacer any monolithic cells can operate. Spacer serves to prevent additional recombination mechanisms, i.e. preventing electrons from the conduction band of the $\mathrm{TiO}_{2}$ active layer are transferred to the carbon counter electrode, without passing through the external circuit [7].

Generally, the structure of monolithic DSSCs consist of layers from top to bottom as follows carbon counter electrode, porous $\mathrm{ZrO}_{2}$ spacer, dyed porous $\mathrm{TiO}_{2}$, and FTO glass substrate as indicated in Figure 1 [5-6, 8]. From the figure, it can be seen that geometrical structure of porous $\mathrm{ZrO}_{2}$ spacer layer is wider than dyed porous $\mathrm{TiO}_{2}$ layer. This geometrical structure is allegedly to result in low cell performance due to direct contact of the electrolyte solution contained in the $\mathrm{ZrO}_{2}$ spacer with the FTO anode. In this paper, we report the results of fabrication of monolithic DSSCs by varying the geometrical structures. By measuring and analyzing the I-V characteristics and the Incident Photon-toCurrent Efficiency (IPCE) of the cells, the effect of geometric structures on cell performance can be known, in order to obtain the geometrical structure that produces the best cell performance.

\section{EXPERIMENTS}

The process of fabrication monolithic DSSC is summarized in Figure 2. The fabrication started with making the geometrical structure design patterns of monolithic DSSC using CorelDraw X7. The design patterns then printed on the transparent plastic sheet.

Next step is the process of transferring the design patterns on the printing screen mesh. Printing screen meshes that used are stainless-based printing screen mesh for $\mathrm{ZrO}_{2}$ and carbon layer and nylon-based printing screen mesh for the $\mathrm{TiO}_{2}$ layer. Printing screen meshes cleaned from dirt and oil using stencil remover paste (No. 5, Ulano Corp., USA) and fabric abrader \& degreaser (No. 23, Ulano Corp.) then dried. Photographic film (Line, Ulano Corp.) was pasted on

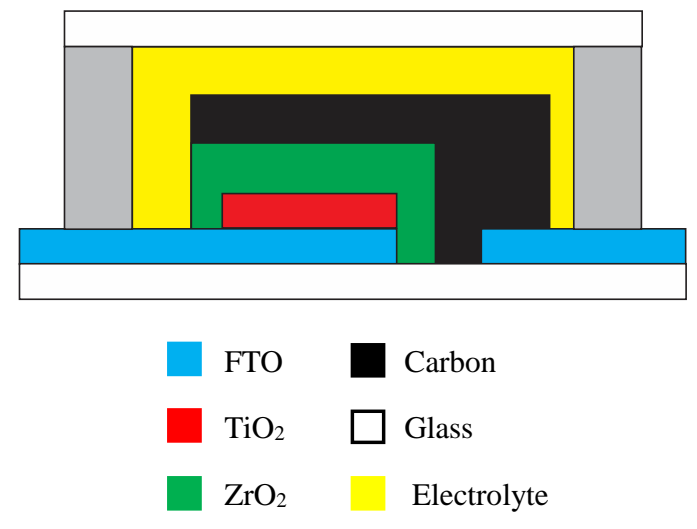

Figure 1. The cross sectional structure of monolithic DSSC. the outer side of printing screen meshes and a mixture of screen emulsion and sensitizer (No. 133, Ulano Corp.) on another side then dried. The design patterns on the transparent plastic sheet then pasted on photographic film and the printing screen meshes were put into solar beam screen maker (3000 TT, Richmond Graphic Products, Inc., USA) for 5 minutes. After that, the transparent plastic sheet was taken and printing screen meshes then cleaned with water until the design patterns emerge on the photographic film, then dried.

FTO substrate glass (TEC15, Dyesol Industries Pty., Ltd., Australia) is cut into $20 \mathrm{~mm}$ x $15 \mathrm{~mm}$ size and sanded on a part of the area of unwanted FTO layer. The sanded FTO substrate glass then washed in acetone (Merck, Germany), soapy water, deionized water, and isopropyl alcohol (PT. Brataco, Indonesia) for 10 minutes respectively using ultrasonic cleaner bath (Branson 3200, Emerson Electric Co., USA).

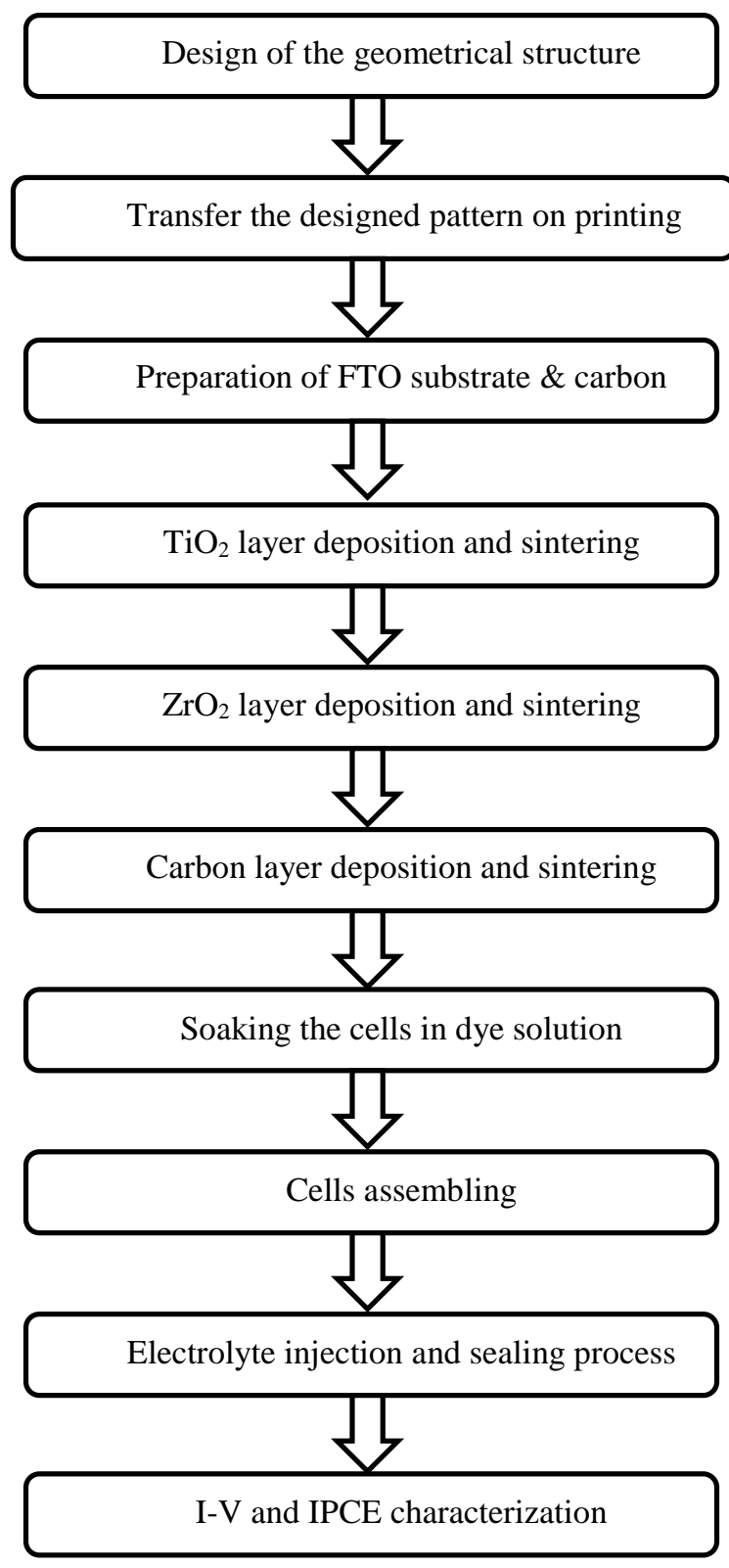

Figure 2. Flowchart of the experiment. 
Carbon paste was made by grounding 0.5 gram carbon nano powder (Aldrich, Germany), 2 gram graphite powder, 0.3 gram ethyl-cellulose (Merck), and 0.25 gram $\mathrm{TiO}_{2}$ powder (P25, Degussa, Germany) in the mortar. 4.25 gram $\alpha$-terpineol (Aldrich) added to the mixture and mixed evenly.

The layers on monolithic DSSC was deposited by screen printing method. $\mathrm{TiO}_{2}$ paste (Dyesol) was printed on the FTO glass substrates and dried at $120{ }^{\circ} \mathrm{C}$ for 10 minutes. Printing and drying are conducted twice to reach an optimal thickness of $12 \mu \mathrm{m}$ before sintered at $500{ }^{\circ} \mathrm{C}$ in conveyor furnace (Lindberg, USA) for 40 minutes. The substrates then immersed in $0,04 \mathrm{mM}$ $\mathrm{TiCl}_{4}$ solution for 30 minutes at $70{ }^{\circ} \mathrm{C}$. After rinsing with deionized water the substrates directly sintered at $500{ }^{\circ} \mathrm{C}$ in conveyor furnace (Lindberg, USA) for 40 minutes.

When the substrates cooled, Zr-Nanoxide paste (Solaronix, Switzerland) was printed on the $\mathrm{TiO}_{2}$ layer and dried at $120^{\circ} \mathrm{C}$ for 10 minutes. Both processes are conducted twice to reach an optimal thickness of 11.5 $15 \mu \mathrm{m}$ before sintered at $450{ }^{\circ} \mathrm{C}$ for 40 minutes in conveyor furnace. When the substrates cooled, a carbon paste was printed on the $\mathrm{ZrO}_{2}$ layer and dried in conveyor oven (Radiant Technology Corp., USA) at $120{ }^{\circ} \mathrm{C}$ for 20 minutes and sintered at $400{ }^{\circ} \mathrm{C}$ for 30 minutes.

The substrates then soaked in a dye solution (Z907 Ru-dye, Solaronix; $0.25 \mathrm{mM}$ ethanol) for 20 hours in dark place. The dyed substrates then assembled with glass using thermoplastic and pressed at $120^{\circ} \mathrm{C}$ for 30 seconds. Electrolyte (EL-HPE, Dyesol) was dropped in the gap between the glasses before sealed with sealing paste (Hermetic Sealing Compound A \& B, Dyesol) and dried.

The photocurrent-voltage (I-V) characterization was using I-V Measurement System (National Instruments Corp., USA) and AM 1.5 solar simulator (Oriel Instruments, Newport Corp., USA) which equipped with a pyranometer. The active area was made to $2.5 \times 10^{-5} \mathrm{~m}^{2}$. The power of simulated light was calibrated at $500 \mathrm{~W} / \mathrm{m}^{2}$. Meanwhile, Incident Photon-toCurrent Efficiency (IPCE) characterization was using Configurable Quantum Efficiency Measurement System (Oriel Instruments, Newport Corp.).

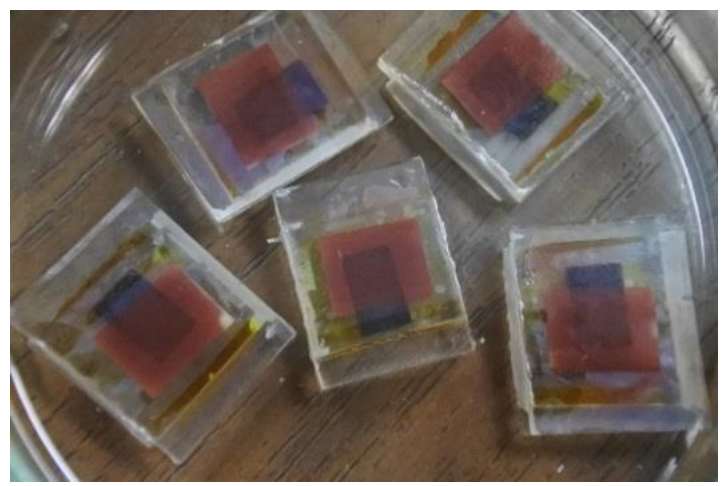

Figure 3. DSSCs that have been fabricated

\section{RESULTS AND DISCUSSION}

There are 4 geometrical structures which were made to be researched. Structure A (Figure 4(a)) has $\mathrm{ZrO}_{2}$ layer (indicated by green) that did not cross over the no-FTO (sanded) area (white), while $\mathrm{TiO}_{2}$ layer (red) half crossed over the no-FTO (sanded) area. Meanwhile, Structure B has $\mathrm{ZrO}_{2}$ layer did not cross over the no-FTO (sanded) area, while $\mathrm{TiO}_{2}$ layer fully crossed over the no-FTO (sanded) area from the anode to cathode FTO (Figure 4(b)).

Structure $\mathrm{C}$ has $\mathrm{ZrO}_{2}$ layer half crossed over the noFTO (sanded) area, while $\mathrm{TiO}_{2}$ layer did not cross over the no-FTO (sanded) area (Figure 4(c)). Meanwhile, the cells with structure D (Figure 4(d)) has $\mathrm{ZrO}_{2}$ layer fully crossed over the no-FTO (sanded) area from the anode to cathode FTO with wider size than $\mathrm{TiO}_{2}$, while $\mathrm{TiO}_{2}$ layer did not cross over the no-FTO (sanded) area.

The photovoltaic parameters (Short circuit current density $\left(\mathrm{J}_{\mathrm{SC}}\right)$, open circuit voltage $\left(\mathrm{V}_{\mathrm{OC}}\right)$, fill factor $(\mathrm{FF})$, and efficiency $(\eta)$ ) of monolithic DSSC were summarized in Table 1. The $\mathrm{I}_{\mathrm{SC}}$ of the cells of structure $\mathrm{A}$ and $\mathrm{B}$ have almost the similar value of 0.111 and $0.110 \mathrm{~mA}$ respectively, and the difference only 0.001 $\mathrm{mA}$. Meanwhile, for the cells with structure $\mathrm{C}$ which has a wider area of the $\mathrm{ZrO}_{2}$ layer than structure $\mathrm{A}$ and $B$ results in $0.086 \mathrm{~mA}$ and the cells with structure D whose $\mathrm{ZrO}_{2}$ layer is the widest area only has $0.021 \mathrm{~mA}$. The highest $\mathrm{V}_{\mathrm{OC}}$ achieved is $0.631 \mathrm{~V}$ for the cell with structure B. Cell with structure A has little smaller $\mathrm{V}_{\mathrm{OC}}$ with $0.611 \mathrm{~V}$.

When the no-FTO area is not crossed by $\mathrm{ZrO}_{2}$ layer (Structure A and B), the cells have relatively higher performance (efficiency) than the cells whose $\mathrm{ZrO}_{2}$ layer crosses over the no-FTO area (Structure C which half crosses and Structure D which fully crosses). The highest efficiency of $0.137 \%$ was achieved by the cell with structure A whose $\mathrm{TiO}_{2}$ layer half crossed over the no-FTO area. The cell with structure $\mathrm{B}$ which has $\mathrm{TiO}_{2}$ fully crossed over the no-FTO area has around $0.002 \%$ lower efficiency than the cell with structure A. This is due to the cell with structure B has more area of the $\mathrm{TiO}_{2}$ layer as photoanode that directly touches and meets with carbon layer and directly contact to FTO cathode. This will lead some excited electrons from dye will recombine without regeneration process of oxidized dye via redox cycle, which in turn will result in decreased current and efficiency.

Usually, there is a thin $\mathrm{TiO}_{2}$ compact layer between FTO anode and mesoporous $\mathrm{TiO}_{2}$. A compact layer is used to increase the photoelectric conversion efficiency on DSSC due to it can improve the TCO surface and prevent the electrolyte from directly contacting the FTO substrate [9]. This layer also provides more electron pathways from $\mathrm{TiO}_{2}$ to FTO for excited electrons from the dye, which facilitate electron transfer and increase the electron transfer efficiency, because of higher density of compact layer, together with a larger contact area and improved adherence between the $\mathrm{TiO}_{2}$ layer and FTO surface [10].

In this study, a $\mathrm{TiO}_{2}$ compact layer deposition was not conducted so the mesoporous structure of $\mathrm{TiO}_{2}$ layer is used as its replacement although it allows the 

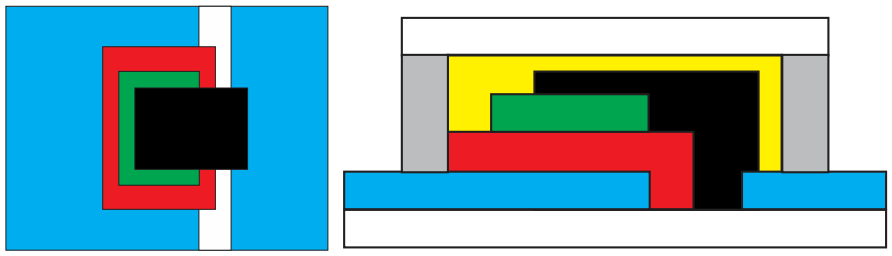

(a)
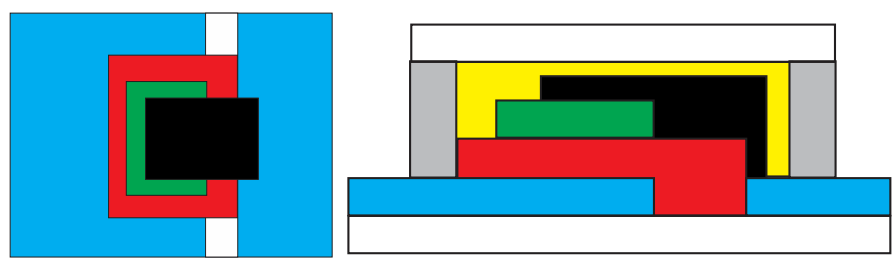

(b)
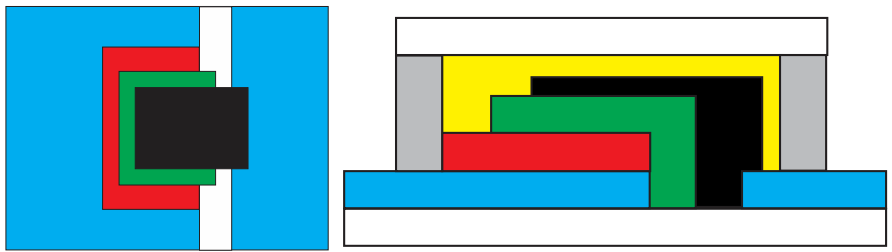

(c)
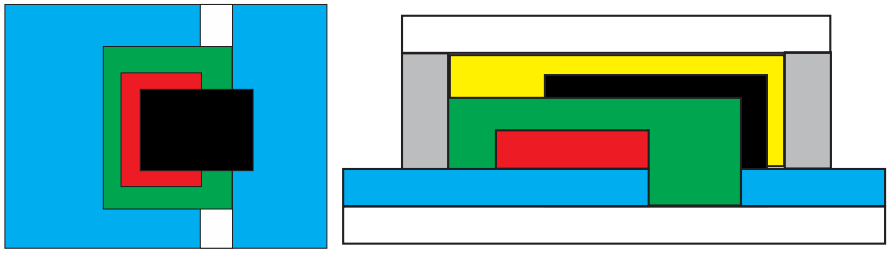

(d)

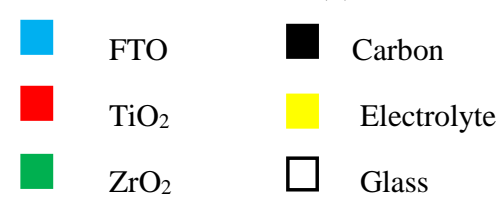

Figure 4. The top and cross-sectional view of monolithic DSSC geometrical structures.

percolation of the electrolyte and the electron transfer on the FTO surface becomes feasible [11]. In the cells of structure $\mathrm{D}$ with $\mathrm{ZrO}_{2}$ layer has wider geometrical dimension than $\mathrm{TiO}_{2}$ layer resulting in the $\mathrm{ZrO}_{2}$ layer which contains electrolyte will be directly contacted with FTO anode. This leads to the recombination of charges so the resulting current decreases and the efficiency becomes lower.

$\mathrm{ZrO}_{2}$ serves to prevent the transfer of electrons from the conduction band of $\mathrm{TiO}_{2}$ active layer to the carbon counter electrode [7], therefore the cells of structure $\mathrm{C}$ should have a higher efficiency than the efficiencies of the cells of structure $A$ and $B$ because it maintains $\mathrm{ZrO}_{2}$ as a spacer separating the $\mathrm{TiO}_{2}$ active layer and the carbon counter electrode layer electrically $[5,6]$. However, from the measure-ment of the electrical characteristics of the cells, the efficiency of the cells of structure $\mathrm{C}$ is even below the efficiencies of the cells of the two structures. Decreasing the efficiency of structure $\mathrm{C}$ to below the efficiencies of the cells of the two structures is most likely due to imperfection of the deposited $\mathrm{ZrO}_{2}$ layer, such as the presence of pinholes or cracks around the edges of the anode FTO. The existence of pinholes and cracks in the $\mathrm{ZrO}_{2}$ layer causes the carbon counter electrode to penetrate it so that the carbon counter electrode is in direct contact with the edge of the anode FTO. This condition causes internal losses thus decreasing the efficiency of the cell. However, structure $\mathrm{C}$ which has an efficiency of $0.101 \%$ is better than the experiment as reported in [12] which used the same geometrical structure as their based geometrical structure and results in only $0.019 \%$. It probably caused the better deposition of each layer in this experiment.

Another factor that influences the results is the thickness of each layer. The thickness of $\mathrm{TiO}_{2}, \mathrm{ZrO}_{2}$, and carbon layer are around $10 \mu \mathrm{m}, 9.75 \mu \mathrm{m}$, and 16.4 $\mu \mathrm{m}$ respectively. As reported [8], optimum thickness of $\mathrm{TiO}_{2}$ layer is maintained below $12 \mu \mathrm{m}$ (in order to ensure the crack-free upper layers), $\mathrm{ZrO}_{2}$ layer is in range $11.5-15 \mu \mathrm{m}$, and carbon layer in range 100-250 $\mu \mathrm{m}$.

Especially for $\mathrm{ZrO}_{2}$ layer, a thicker layer results in a longer lifetime of electron in the active $\mathrm{TiO}_{2}$ layer and as a consequence, higher $\mathrm{J}_{\mathrm{SC}}, \mathrm{V}_{\mathrm{OC}}$, and efficiency values. With a low $\mathrm{ZrO}_{2}$ layer thickness makes no additional current loss because of $\mathrm{ZrO}_{2}$ 's high insulating potential does not permit electrons to pass across the border between $\mathrm{TiO}_{2}$ and carbon, the electrons will prefer to flow to the external circuit lane through the 
TABLE 1

THE PHOTOVOLTAICS PARAMETERS OF MONOLITHIC DSSC ON DIFFERENT GEOMETRICAL STRUCTURE

\begin{tabular}{|l|l|l|l|l|l|l|}
\hline Structure & $\mathbf{J}_{\mathbf{S C}}(\mathbf{m A})$ & $\mathbf{V}_{\mathbf{O C}}(\mathbf{V})$ & $\mathbf{F F}$ & $\boldsymbol{\eta}(\mathbf{\%})$ & $\begin{array}{l}\text { Average } \\
\boldsymbol{\eta}(\%)\end{array}$ & $\begin{array}{l}\text { Deviation } \\
\text { Standard }\end{array}$ \\
\hline A & 0.111 & 0.611 & 0.254 & 0.137 & 0.066 & 0.066 \\
\hline B & 0.110 & 0.631 & 0.243 & 0.135 & 0.048 & 0.075 \\
\hline C & 0.086 & 0.590 & 0.249 & 0.101 & 0.038 & 0.054 \\
\hline D & 0.021 & 0.101 & 0.331 & 0.005 & 0.003 & 0.001 \\
\hline
\end{tabular}

$\mathrm{TiO}_{2}$ conduction layer. A thicker layer affects a stronger insulation that results in a higher shunt resistance [8], [13].

The other factor is cell leakage when electrolyte was injected. After sealed by sealing paste, there is a possibility that the previously injected electrolyte can still get out of the cell through small gaps. It is influencing to not optimal electron cycle process. Little factors such as temperature, pressure, and humidity also influence the cell performance.

Overall, the low efficiencies observed on all geometrical structure of monolithic DSSC were mainly caused by the low values of FF. It can be seen in Figure 5 that all of the geometrical structure showed very steep curves that represent low values of fill factor. Fill factor is strongly related to the internal resistance values, such as series resistant (RS) and shunt resistance (RSH) [12]. To make ideal solar cells, RS should be to zero and in contrary, RSH should be infinite or basically, RS must be lower than RSH. In this study, the fill factor values are less than 0.4 as shown in Table 2. This is probably caused by electrical contact between anode FTO and cathode FTO. From Figure 3 shows that injected electrolyte into the cell is expected to be absorbed only by zirconia, but the electrolyte spreads to the entire cell surface and covers up the anode FTO and cathode FTO that resulting electrical contact.

IPCE is defined as the ratio of the number of electrons in the external circuit produced by an incident photon at a given wavelength [9]. Figure 6 shows IPCE spectrum for each geometrical structure of monolithic DSSC. A high IPCE value shows that electron transfer process from dye to conduction band of semiconductor occurs effectively. Furthermore, high IPCE values indicate electron transfer from $\mathrm{I}^{-}$to oxidized dye occurs effectively [14]. The higher IPCE value, the more photons are converted into current [15].

TABLE 2

SERIES AND SHUNT RESISTANCE ON EACH GEOMETRICAL STRUCTURE DATA

\begin{tabular}{|c|c|c|}
\hline Structure & $\begin{array}{l}\text { Shunt } \\
\text { Resistance ( } \Omega)\end{array}$ & $\begin{array}{l}\text { Series } \\
\text { Resistance ( } \Omega)\end{array}$ \\
\hline A & 5068.68 & 6008.90 \\
\hline B & 4825.76 & 6704.81 \\
\hline $\mathrm{C}$ & 6040.56 & 7246.84 \\
\hline $\mathrm{D}$ & $\mathrm{NaN}$ & $\mathrm{NaN}$ \\
\hline
\end{tabular}

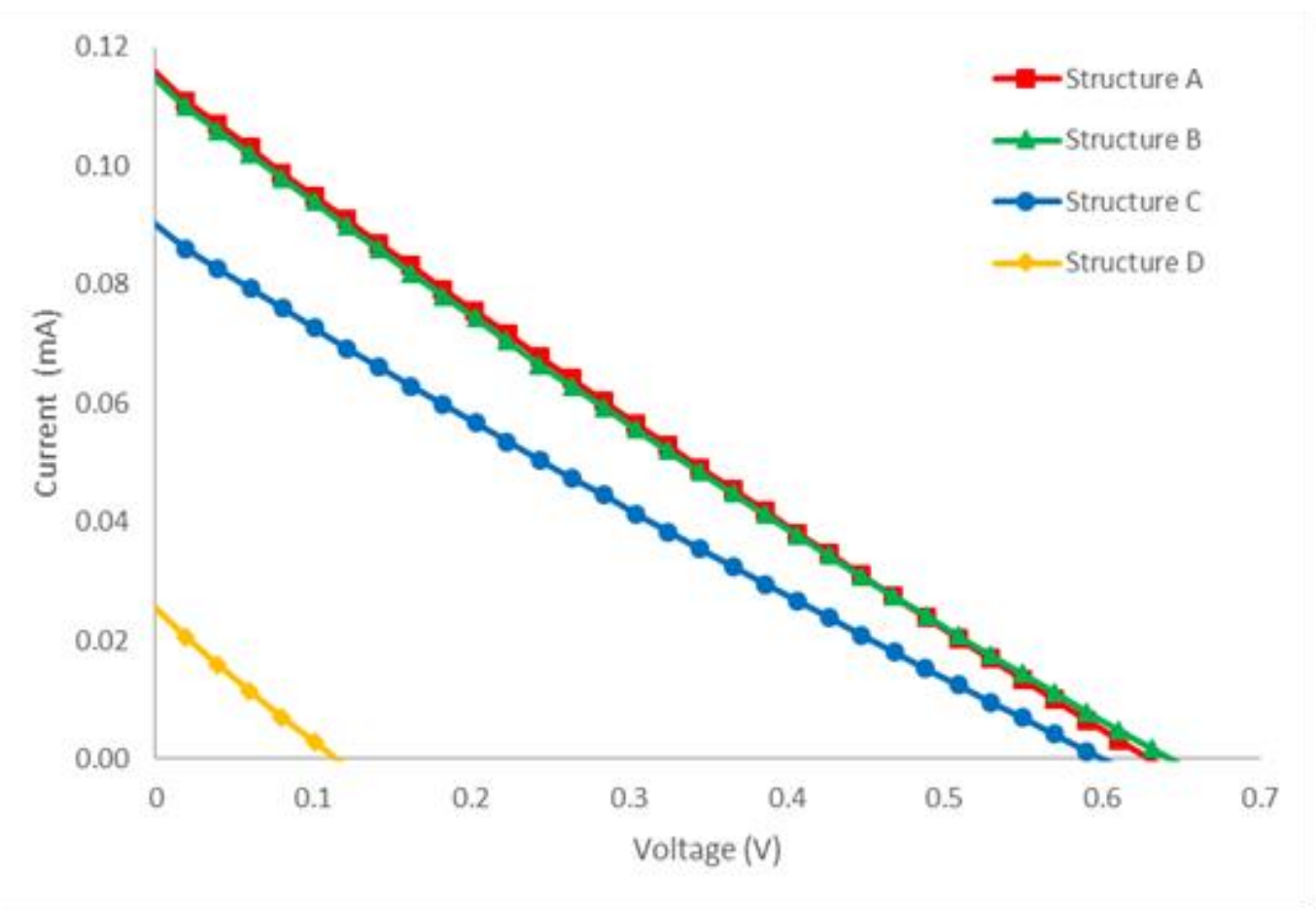

Figure 5. The photo current - voltage graph for each geometrical structure of monolithic DSSC based on Figure 4 


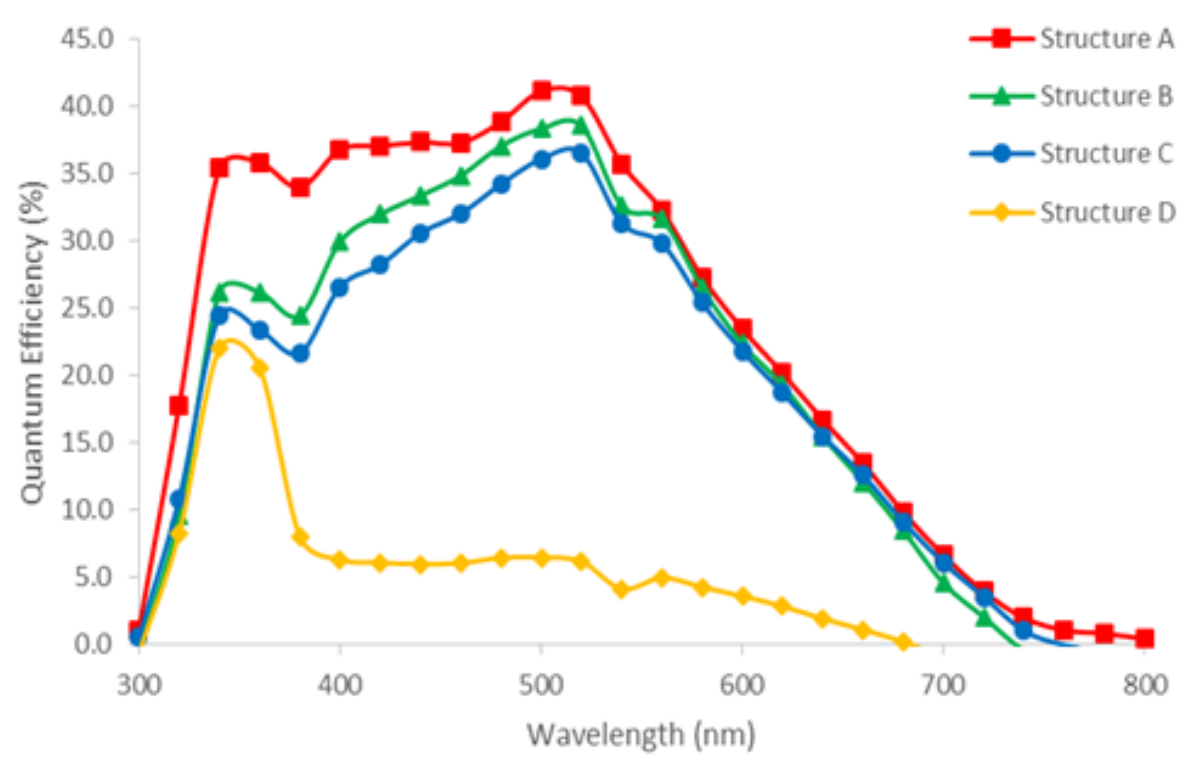

Figure 6. The graph of quantum efficiency for each geometrical structure of monolithic DSSC based on Figure 4

Figure 6 shows that the enhancement of photon absorption is in the wavelength range of visible light with the maximum peak at a wavelength of $510 \mathrm{~nm}$ except for structure D which the quantum efficiency escalates until reaches the peak at $340 \mathrm{~nm}$ wavelength then decreases drastically. It means at that wavelength, occurs the highest conversion of photons to current for structure D. It caused of the photon that converted to current only comes from the $\mathrm{TiO}_{2}$ semiconductor and only a few from the dye. In the cell of structure $\mathrm{D}$, the $\mathrm{TiO}_{2}$ layer fully covered by $\mathrm{ZrO}_{2}$ layer so when the cells soaked in the dye solution, only a few of dye that absorbed by $\mathrm{TiO}_{2}$ layer through pores of $\mathrm{ZrO}_{2}$.

Apparently, in order for monolithic DSSC to provide high performance various factors that can eliminate recombination pathways should be used so that any internal losses can be avoided, such as a thin $\mathrm{TiO}_{2}$ compact layer over FTO anode, perfect $\mathrm{TiO}_{2}$ and $\mathrm{ZrO}_{2}$ layers without pinholes and cracks, and others.

\section{CONCLUSION}

Low-cost of the monolithic design of DSSCs with various of geometrical structures have been fabricated with only using single FTO substrate and carbon as the counter electrode. Based on the result of I-V and IPCE characterization for each geometrical structure, most likely due to imperfection of the $\mathrm{ZrO}_{2}$ layer deposited the cells with geometrical structure $\mathrm{A}$ which $\mathrm{ZrO}_{2}$ layer that did not cross over the no-FTO (sanded) area, while $\mathrm{TiO}_{2}$ layer half crossed over the no-FTO area has the highest performance of all with efficiency of $0.137 \%$ and highest photon absorption that converted to current occurs around wavelength of $510 \mathrm{~nm}$.

\section{ACKNOWLEDGEMENT}

This research was financially funded by the program of INSINAS Kemenristekdikti through contract number of 056 / P / RPL / LIPI / INSINAS-2 / $\mathrm{V} / 2017$. Also we would like to thank the members of Material and Devices for Solar Cells research group at the Research Center of Electronics and Telecommunication, Indonesian Institute of Sciences (P2ET-LIPI) for the help and the cooperation during the research activities.

\section{REFERENCES}

[1] H. Hasnawiyah, "Perancangan Pembangkit Listrik Tenaga Surya Di Pulau Saugi," Jurnal Riset dan Teknologi Kelautan, vol. 10, pp. 169-180, 2012.

[2] (2017) The National Geographic website. [Online]. Available: https://environment.nationalgeographic.com

[3] D. Susanti, M. Nafi, H. Purwaningsih, R. Fajarin and G.E Kusuma, "The Preparation of Dye Sensitized Solar Cell (DSSC) from $\mathrm{TiO}_{2}$ and Tamarillo Extract," Procedia Chemistry, vol. 9, pp. 3-10, 2014.

[4] B. O’Regan and M. Grätzel, "A Low-Cost, High-Efficiency Solar Cell Based on Dye-Sensitized Colloidal $\mathrm{TiO}_{2}$ Films," Nature, no. 353, pp. 737-740, 1991.

[5] K. Kalyanasundaram, Dye-Sensitized Solar Cells, 1st ed., Lausanne, Siwtzerland: EPFL Press, 2010.

[6] S. Ito and K. Takahashi, "Fabrication of Monolithic DyeSensitized Solar Cell Using Ionic Liquid Electrolyte," International Journal of Photoenergy, vol. 2012, pp. 1-6, 2012.

[7] S. J. Thompson, N. W. Duffy, U. Bach, Y.-B Cheng, "On the Role of the Spacer Layer in Monolithic Dye-Sensitized Solar Cells," Journal of Physic Chemistry C, vol. 114, pp. 2365-2369, 2010.

[8] L. Vesce, R. Riccitelli, G. Mincuzzi, A. Orabona, G. Soscia, T.M. Brown, A. Di Carlo and A. Reale, "Fabrication of Spacer and Catalytic Layers in Monolithic Dye-Sensitized Solar Cells," IEEE Journal of Photovoltaics, vol. 3, pp. 1004-1011, 2013.

[9] H.T. Chou, K.M. Lin and H.C. Hsu, "Fabrication of $\mathrm{TiO}_{2}$ compact layer precursor at various reaction times for dye sensitized solar cells," Microelectronics Reliability, vol. 55, pp. 2208-2212, 2015.

[10] H. Yu, S. Zhang, H. Zhao, G. Will and P. Liu, “An efficient and low-cost $\mathrm{TiO}_{2}$ compact layer for performance improvement of dye-sensitized solar cells," Electrochimica Acta, vol. 54, pp. 1319-1324, 2009.

[11] A.O.T. Patrocinio, L.G. Paterno, and N.Y Murakami Iha, "Layer-by-layer $\mathrm{TiO}_{2}$ films as efficient blocking layers in dyesensitized solar cells," Journal of Photochemistry and Photobiology A: Chemistry, vol. 205, pp. 23-27, 2009.

[12] A. Istiqomah, M. Rokhmat and N.M Nursam, "Analysis of Catalytic Material Effect on the Photovoltaic Properties of Monolithic Dye-sensitized Solar Cells," Jurnal Elektronika dan Telekomunikasi, vol. 17, pp. 30-35, Dec. 2017. 
[13] A. Hinsch, R. Kinderman, M. Spath, E. Rijnberg and J. A. M. von Roosmalen, "The performance of dye-sensitized solar cells with a one-facial, monolithic layer built-up prepared by screen printing," presented at the 2nd World Conference and Exhibition on Photovoltaic Solar Energy Conversion, Vienna, Austria, 1998.

[14] K. Hara, T. Horiguchi, T. Kinoshita, K. Sayama, H. Sugihara and H. Arakawa, "Highly efficient photon-to-electron conversion with mercurochrome-sensitized nanoporous oxide semiconductor solar cells," Solar Energy Materials and Solar Cells, vol. 64, pp. 115-134, 2000.

[15] K. Varghese and C. A. Grimes, "Appropriate Strategies for Determining The Photoconversion Efficiency of Water Photoelectrolysis Cells: A Review with Examples Using Titania Nanotube Array Photoanodes Oomman," Solar Energy Materials and Solar Cells, vol. 92, pp. 374-378, 2008. 